\title{
Problems and Countermeasures of Performance Management Operation in National Procurement Programs
}

\author{
Shan-Nv SONG ${ }^{a}$, Gen-Zhe HUANG ${ }^{\text {b, }}$ \\ Changchun University of Science and Technology, Administrative Office of National Assets, Jilin \\ Changchun 130022, PR China \\ asongshannv@cust.edu.cn, bhuanggenhze@cust.edu.cn \\ *Corresponding author
}

Keywords: Public value, Government procurement, Purchasing form, Performance management.

\begin{abstract}
This research is focused on the several problems that have presently existed in national procurement programs such as high price compared to market price, complicated purchasing procedures, and long period of purchasing. The problem-solving countermeasures is to introduce the performance appraisal system into national procurement programs to provide benefits through diversifying the evaluation systems, making society and people more be connected with supervision, normalizing the national procurement programs, and generating more transparent purchasing information. In addition, the performance appraisal system can boost national procurement to be developed into more standardization and institutionalization.
\end{abstract}

\section{Introduction}

Performance management (PM) practice in the government procurement certainly promoted efficient use of government financial fund, enhanced the management efficiency in administrative purchasing department, built up the understanding and trusting for the administrative section, and facilitated positive operation of national economic. However, along with the increase of the government procurement, the effect of PM on the government procurement is not sufficient. Until now, the relative problems existed in the government procurement programs in China, including lack of effective performance appraisal system and scientific PM assessment criteria, and insufficient institutional assurance, social and public people participating in, less openness of appraisal activity, non-standardized purchasing operation, and non-transparent information etc. In addition, the influence of the non-standardization on government procurement generated serious dispute and query: why the public need the government procurement? Why are the procedures so complicated and periods so long? How is the PM operated? What item or how much public fund does the government procurement save for people [1-5]? Therefore, we will study and explore the countermeasures of the problems related to PM operation to further improve government fund efficiency through focusing on the existing problems of the PM operation in government procurement.

PM opreation in the government procurement normally relies on national power, at the same time, it pay more and more attention to public satisfactory index as the public value is of publicity. In addition, PM operation cannot seperate with the public participation, which is conducive to promote democratic management and to increase confidence on the government. Moreover, as the goverment procurement is one kind of behaviors where purchasers have to satisfy the public requrirment and to realize the government function, taxpayers consign purchasing power to every level of government throuth legal procedures. It is necessary for the relavant information, pattern, and programs to be open and the purchasing contract must be signed under the open and fair competion in order that the agent or public fund users cannot depart from the public value. All of the process aims for realizing the targent of the public value in the government procurement. The satisfaction to the public requirement will construct the infrastructures of the public value. The degree of the public particitation and selection will decide if the target is come true. Therefore, the degree of the public participating in the $\mathrm{PM}$ operation is just the public value. 


\section{The Main Problems of PM Operation in the Government Procurement}

\section{Heavy Administerization Tendency in PM Operation}

The fund characteristic of the government procurement is expenditure public fund. For the most of the purchasing body, the purchasing fund comes from fiscal allocation. It would be subjected to the uniform financial control. For example, the purchasing items, schedule of the government procurement operation, and the method must be strictly restrained. Big purchasing items would be responsible for arrangement of implementing fund situation [6-8]. If the fund did not expend until the end of year, the purchasing body will face the fund reclamation risks from the administrative financial department. Therefore, this kind of the government procurement only cater to the government budget, it is not operated to cater to the purchasing main body, and as a result, it would generate the heavy administeriation tendency in PM operation.

\section{Unbalanced Duty and Authority in PM Operation}

Administrative office is tightly subjected to the financial fund provider at the government procurement program. The financial fund department carries out the duties not only in audit and also in assessment of items of government procurement. Under such circumstance, the management power of the administrative office must be weakened at the condition of strong authority of financial department [9-10]. In another words, the financial department is not only the policy maker, but also judicators in approval of budget for the government procurement. Ironically, this financial department is also responsible for the government procurement task development such as purchasing daily administrative office supplies and decorating their official buildings.

Normally, the budget approval criteria are strongly connected with national financial revenue and gross value of production. Therefore, the purchasing department is located in lower level when waiting for approval by the financial fund department. If approved budget was cut as bad financial situation, the changed fund supplement cannot meet the requirement asked by the purchasing department. As a result, the different budget quota will lead to different purchasing results. Of course, the approval by the financial department is controlled by national macro-financial revenue and expenditure, it does not aim for any specific institution or any purchasing item, however, it objectively gives rise to the unbalanced budget fund supplies and applications.

\section{Unscientific PM Operation}

Sometimes, the PM operation is unscientific as it was being overemphasized on open tendering. In fact, the type of government procurement program has many ways including open tendering, enquiry, single-source operation, and competitive negotiation. Shortcoming of the open tendering is long period of purchasing, complex program, low efficiency, and high cost of purchasing although it also has some specific strong points in the area of open, just, and fair competition. As the procedures of the government procurement related to many steps or links, sometimes, the administrative department select the easy and illegal way, which would lead to unscientific PM operation.

Some institute did not seriously study the relative regulation and judicial law of the "Government purchase law". As a result, they did not thoroughly understand and master the relative regulatory framework and purchase procedures, and were lack of consciousness of purchasing by law, even give rise to the situation of violating the relative law. For example, in order to purchase intended products, some institutes directly or indirectly decide the dealer or goods brand, and some unlawfully break up the whole purchasing items into parts in order to avoid government procurement programs, even some acquire illegitimate benefits by applying other non-government procurement program ways through arguing short purchasing time, over professional, and unexpected problems etc. as a result, it will also lead to low PM operation.

\section{Non-Optimized Operation Flow in the Performance Management}

The government procurement operation is an important form of financial expenditure. The budget fund expenditure behaviors must generate fixed assets through purchasing specific items. the purchasing, using, managing, and scrapping for the fixed assets is one of integrated close cycle. The 
scientific management of fixed assets is the extension of PM operation in the government procurement. All assets purchased through the government procurement must be subjected to the unique management system. For the fixed assets, one of integrated assets management system must complete the following function such as basic data collection, information transfer and related media management in order to implement the account management, data report, and in-time data collecting. However, the assets management systems between the financial department and purchasing institution is not smoothly connected, and sometimes cannot implement the data exchange task [11-12].

\section{Countermeasures of the National PM Operation based on the Public Value}

\section{Reforming Budget Program to Provide Suitable Operating Platform in the Government Procurement}

Along with gradual improvement of social market economy system and fiscal system, the public pay much attention to the use of fiscal fund and the PM operation. Budget performance management is main part of the PM operations, it requires to integrate the PM idea to the whole process of budgeting, implementing, and supervising. It also demands the government department to timely improve the service quality and to effectively enhance the use efficiency of fiscal fund.

\section{Strengthening Supervision Mechanism to Effectively Give Power Restriction in the Government Procurement}

In the modern democratic society, the public release certain power to some organization that can be able to implement its duty in order to protect their regular life. So the transferred power of the government procurement is a public power. Its implementing must be subjected to the target of public interests and benefits. However, the corruption or the public power dissimilation would be generated if the public power implementing process is departed from the public interesting, namely, the power exerciser illegally asks for private or clique interesting.

\section{Construction of Efficient Appeal and Relief Mechanism Through Improving Legislation}

From the point view of international legislation, the government procurement program is important to construct and improve the mechanism of query, appeal and relief. In addition, it is also the most important guarantee for effectively operating and implementing the target. Whereas, at present national legal system is not totally covered all areas of the government procurement program and lack of efficiency, we should improve the relative mechanism of query, appeal and relief, and should query or appeal some unlawful situations through negotiation, arbitration, judiciary and administration measures in order to protect the legislation rights or interests of supplier, contractor, and service provider.

\section{Setting Up the Evaluation index to Provide the Operational Guideline for the PM Operation}

One of the important content of the PM operation is to determine the PM operational index that used as evaluation tools. The construction of the PM operational index is the key steps for the PM operation, and its scientific nature will decide the results of the PM operation. According to the academic research, until now the reached consensus of $4 \mathrm{E}$ index-economic, efficiency, effectiveness, equity-can systematically cover the target and value orientation of the public management and service. In addition, the scientific, systematic, and operational PM will be improved if we are further refining and resolving the index.

\section{Summary}

The implementing of the PM operation would face with many challenges. In addition, the construction of the coordinated management system is still a long way to go. First, all levels of the government and department must strengthen the cognition and understanding of the PM operation in the manner of the government procurement. At present some personnel cannot clearly understand the 
development trend of the PM operation, so they just take the negative or waiting and seeing attitude for the PM operation. As a result, some reform measures is difficult to be carried out. Second, not only the purchasing scope but also the scale would be increased. Moreover, the disparity of implementing the government procurement in different area is large, it leads to lower efficiency in promoting the reformation of the PM operation. Third, the deviation between specific regulation design and practical operation is large, the problems or big gap exists in the area between the design of some procedure, operating method, implementing links, and practical operational environment. These problems also affect the benefits and efficiency of the government procurement. Fourth, the function of the supervision must be carried out totally. All levels of government or related institution must enhance the study capability, deeply carry out the reformation, and settle the problems through implementing effective countermeasures.

\section{Acknowledgement}

This research has been supported by the Youth Fund XQNJJ-2016 and KYC-JC-XM-2 Project, Authors greatly appreciate their support.

\section{References}

[1] Pollitt C. Performance audit in western Europe: trends and choices [J]. Critical Perspectives on Accounting, 2003, 14(1-2):157-170.

[2] Pat Barrett. Performance auditing-addressing real or perceived expectation gaps in the public sector [J]. Public Money\& Management. 2012(2):129-136.

[3] Shu-Qiang CHUI. Discuss of PM operational index system in local government[J]. Statistic Research, 2006(3): 45-48(in Chinese).

[4] Yong FU, Xiu-Hong YANG. Macro-analysis of PM operation between fiscal expenditure and purchasing[J]. China Government Procurement, 2007(10): 15-17(in Chinese).

[5] Ai-Lin XIAO. Innovative research on national PM operation based on the public value[D]. Jilin University, 2013(in Chinese).

[6] Min-Zhong HU. Discuss of the public value[J]. Transaction of Beijing Normal University, 2008(1): 34-37(in Chinese).

[7] Ming-Jin HUANG. Factor analysis of PM operational efficiency[J]. China government procurement, 2015(3): 89-91(in Chinese).

[8] Ting GE. Brief discuss of national public finance and purchasing system[J]. Market Weekly, 2006(1): 25-28 (in Chinese).

[9] James Guthrie. The Contested Nature of Performance Auditing in Australia [J]. International Journal of Auditing, 2004(6):23-26.

[10] Kristin Reichborn. Political accountability and performance audit: The case of the auditor general in Norway [J]. Public Admin. 2013. 91 (3): 102-109.

[11] Robert Rothery. China's legal framework for public procurement [J], Journal of Public Procurement, 2003(3):370-388.

[12] Khi V Thai, Rich Grimm. Government Procurement: Past and Current Developments[J], Journal of Public Budgeting, Accounting \& Financial Management, 2000 (2): 231-247. 